\title{
Derin Öğrenme Yöntemi ile İç Anadolu Bölgesi ve Çevresi Hava Kirliliği Tahmini
}

\author{
Sümeyye Aydın ${ }^{1 *}$, Murat Taşyürek ${ }^{2}$, Celal Öztürk ${ }^{3}$ \\ 1* Kayseri Üniversitesi, Mühendislik Mimarlık ve Tasarım Fakültesi, Bilgisayar Mühendisliği Bölümü, Kayseri, Türkiye, (ORCID: 0000-0002-4031-6806), \\ sumeyyeaydin@kayseri.edu.tr \\ ${ }^{2}$ Kayseri Üniversitesi, Mühendislik Mimarlık ve Tasarım Fakültesi, Bilgisayar Mühendisliği Bölümü, Kayseri, Türkiye, (ORCID: 0000-0001-5623-8577), \\ murattasyurek@kayseri.edu.tr \\ ${ }^{3}$ Erciyes Üniversitesi, Mühendislik Fakültesi, Bilgisayar Mühendisliği Bölümü, Kayseri, Türkiye, (ORCID: 0000-0003-3798-8123), celal@erciyes.edu.tr
}

(International Symposium on Multidisciplinary Studies and Innovative Technologies (ISMSIT) 2021 - 21-23 October 2021)

(DOI: 10.31590/ejosat.1019618)

ATIF/REFERENCE: Aydın, S., Taşyürek, M. \& Öztürk, C. (2021). Derin Öğrenme Yöntemi ile İç Anadolu Bölgesi ve Çevresi Hava Kirliliği Tahmini. Avrupa Bilim ve Teknoloji Dergisi, (29), 168-173.

\section{Öz}

Sanayideki gelişmeler, nüfus artışı, çarpık kentleşme gibi sebepler hava kirliliğini artırmaktadır. Hava kirliliği tüm ekolojiyi ve insan sağlığını olumsuz yönde etkilediği için küresel anlamda önemlidir. Hava kirliliğinden kaynaklı oluşabilecek tehlikeli durumları önleyebilmek için önceden tedbirler alınmalıdır. Hava kirliliğini etkileyen unsurların önceden tahmin edilmesi ile oluşabilecek tehlikeli durumları önlemek mümkün olabilir. Partikül madde (PM) değeri hava kirliliğinin derecesini belirtmek için yaygın olarak kullanılan bir parametredir. Aerodinamik çapı $10 \mu \mathrm{m}$ 'den küçük olan partiküller madde olarak tanımı yapılan PM10 parametresi, ülkemiz için belirlenen sınır değerleri aşmaktadır ve dolayısıyla PM10 konsantrasyonunun artışında önlem alınması ciddi önem taşımaktadır. Bu çalışmada hava kalitesinin belirlenmesinde büyük rolü olan PM10 parametresinin değerlerinin tahmini üzerine araştırmalar yapılmıştır. Bu çalışmada, Meteoroloji Genel Müdürlüğü’ne ait İç Anadolu Bölgesi ve çevresindeki istasyonlara ait gerçek ölçüm verileri kullanılmıştır. Hava kalitesi indeksinin hesaplanmasında kullanılan kirletici madde parametrelerinin değerleri kullanılarak PM10 parametresinin değeri tahmin edilmiştir. Son yıllarda tahmin işlemlerinde derin öğrenme yöntemleri sıklıkla kullanılmaktadır. Derin öğrenme yöntemlerinden uzun süreli kısa bellek ağı (LSTM) modeli zamansal olarak bir önceki durumdan etkilenen veri kümelerinde yaygın olarak kullanılmaktadır. Anlık hava kalitesi bir önceki durumlardan etkilendiğinden dolayı bu çalışmada LSTM derin öğrenme modeli bir ilin PM10 değerlerinin tahmin edilmesi için önerilmiştir. Önerilen LSTM tabanlı modelin performansı klasik derin ö ğrenme yöntemi (DL) ile karşılaştırılmıştır. Yöntemlerin başarım performansını irdelemek için değerlendirme kriteri ortalama hata kare kökü (RMSE) ve ortalama mutlak hata (MAE) değerleri kullanılmıştır. Deneysel değerlendirmeler, önerilen LSTM yönteminin DL yöntemine göre PM10 değerlerinin tahmininde daha başarılı tahminler elde ettiğini göstermektedir. Ayrıca LSTM yönteminin veri kaybı olduğu durumlarda DL yöntemine kıyasla veri sayısından daha az etkilendiği görülmüştür.

Anahtar Kelimeler: Lstm, Derin Öğrenme, Hava Kirliliği Tahmini, PM10.

\section{Air Pollution Prediction for Central Anatolia Region and Its Surroundings with Deep Learning Method}

\begin{abstract}
Developments in industry, population growth and unplanned urbanization are the main factors of air pollution increase. Since air pollution negatively affects all ecology and human health, it has global importance. Precautions should be taken to prevent dangerous situations that may arise from air pollution. Hazardous situations that may occur can be prevented by predicting the factors affecting air pollution. The particulate matter (PM) value is a commonly used parameter to indicate the degree of air pollution. The parameter PM10, which is defined as particles with an aerodynamic diameter less than $10 \mu \mathrm{m}$, exceeds the limit values determined for our country, and therefore it is of great importance to take precautions in the increase of PM10 concentration. In this study, the values of the PM10 parameter, which has a great role in determining the air quality, is tried to be predicted. In this study, real measurement data of the Central Anatolian Region and surrounding stations belonging to the General Directorate of Meteorology were used. The value of the PM10 parameter was estimated by using the values of the pollutant parameters used in the calculation of the air quality index. In recent years, deep learning methods have been frequently used for prediction. The long-term short-memory network (LSTM) model, one of the deep learning methods, is widely used in datasets that are temporally affected by the previous situation. Since the previous conditions affect the instantaneous air quality, LSTM deep learning model is proposed to predict PM10 values of a city. The performance of the proposed LSTM-based model is compared with the classical deep learning method (DL). Root mean error square (RMSE) and mean
\end{abstract}

\footnotetext{
* Sorumlu Yazar: Kayseri Üniversitesi, Mühendislik Mimarlık ve Tasarım Fakültesi, Bilgisayar Mühendisliği Bölümü, Kayseri, Türkiye, ORCID: 0000-0002-4031-6806, sumeyyeaydin@kayseri.edu.tr
} 
absolute error (MAE) values were used to evaluate the performance of the methods. Experimental evaluations show that the proposed LSTM method is more successful in estimating PM10 values than the DL method. In addition, it has been observed that the LSTM method is less affected by the number of data compared to the DL method in cases where there is data loss.

Keywords: Lstm, Deep Learning, Air Pollution Prediction, PM10.

\section{Giriş}

Hava kirliliği dünyamızı tehlikeye sokan en önemli etmenlerden bir tanesidir (Li vd., 2019). Sanayideki gelişmeler, nüfus artışı, çarpık kentleşme, tarım ilaçları ve kimyasalların kullanımının artması gibi sebepler hava kirliliğini artırmaktadır. Hava kirliliği tüm ekolojiyi, insan sağlığını ve davranışlarını olumsuz yönde etkilediği için çok önemlidir ve küresel anlamda bir sorun teşkil etmektedir. Hava kirliliği problemini niceliksel olarak gösterebilmek için çeşitli parametreler kullanılmaktadır. Bunlardan biri de hava kalitesi indeksidir (HKİ); yaygın olarak kullanılan HKİ sınıflandırma sisteminde hava kirliliğinin boyutuna göre değerlendirme yapılır. HKİ indeksinin hesaplanması ülkelerin belirlediği kriterlere göre değişiklik gösterir. Türkiye'de ulusal hava kalitesi indeksi, EPA hava indeksinden uyarlanarak oluşturulmuştur ve 5 temel kirletici maddenin konsantrasyonuna göre hesaplanmaktadır. Hesaplamada kullanılan bu kirletici maddeler partikül maddeler (PM10), karbon monoksit (CO2), kükürt dioksit (SO), azot dioksit (NO2) ve ozon (O3) dur (Hava Kalitesi Değerlendirme, 2008).

Hava kalitesi kirletici parametrelerin birleşiminden etkilenmektedir. Kirleticiler havaya, suya ve toprağa bulaşmaktadır. Bulaşan bu kirletici maddenin canlıların vücuduna girerek sağlığını olumsuz etkilemesi kaçınılmazdır. Kirletici parametreler Tablo 1'de listelenmiştir (Kirletici Parametre Ayarları, 2021). Bu parametrelerin en önemlilerinden bir tanesi de Partikül madde (PM)'dir. PM seviyesi küresel çapta bir sorundur. Literatürde yapılan çalışmalar PM'nin insan üzerinde toksik etki yarattığını göstermiştir (Lu vd., 2015). Yüksek seviyedeki PM konsantrasyonuna k1sa süreli maruz kalma nedene özgü mortaliteyi artırır (Janssen vd., 2013). Uzun süreli maruz kalma ise geçici kardiyopulmoner etkilere, solunum hastalıklarına ve akciğer kanserine neden olabilmektedir (Scapellato vd., 2009, Wu vd., 2014, Turner vd., 2011). PM10 aerodinamik çap $10 \mu \mathrm{m}$ veya daha küçük olan partiküler maddelere denmektedir. Hava Kirliliği Kontrolü Yönetmeliğine göre PM10 konsantrasyonu y1lda 35 defadan fazla $50 \mu \mathrm{g} / \mathrm{m}^{3}$ ü geçmemelidir (Hava Kalitesi Değerlendirme, 2008). Ülkemizde ise PM 10 için belirlenen sınır değerlerin aşıldığı görülmektedir (Zeydan, 2021).

PM kirliliğinin tüm zararlı etkileri dikkate alındığında ve ülkemizdeki pm sınırının aşıldığı görüldüğünden, bu kirleticinin gelecek konsantrasyonlarının belirlenmesi ve zararların önlenmesi açısından büyük önem taşımaktadır.

Tablo 1. Çalışmada Kullanılan Kirletici Maddeler (Kirletici Parametre Ayarları, 2021)

\begin{tabular}{|c|c|c|c|}
\hline Parametre Adı & Sembolü & Birimi & Açıklama \\
\hline Partikül Madde & PM10 & \multirow{7}{*}{$\mu \mathrm{g} / \mathrm{m} 3$} & $\begin{array}{l}10 \mu \mathrm{m} \text { veya daha küçük çaptaki partiküllere PM10 denilmektedir. Havada asılı kalan } \\
\text { ve solunabilen birçok partikülün karışımıdır. Partiküler madde doğal ve antropojenik } \\
\text { faaliyetler sonucu oluşur. Yangın dumanı, motorlu taşıtların egzozları, fabrikalar gibi } \\
\text { kaynaklardan yayılmaktadır. }\end{array}$ \\
\hline Partikül Madde & PM2.5 & & $\begin{array}{c}2.5 \mu \mathrm{m} \text { veya daha küçük çaptaki partiküllere PM2.5 denilmektedir. Havada asılı } \\
\text { kalan ve solunabilen birçok partikülün karışımıdır. Partiküler madde doğal ve } \\
\text { antropojenik faaliyetler sonucu oluşur. Yangın dumanı, motorlu taşıtların egzozları, } \\
\text { fabrikalar gibi kaynaklardan yayılmaktadır. }\end{array}$ \\
\hline Kükürtdioksit & $\mathrm{SO} 2$ & & $\begin{array}{c}\text { Kükürt oranı yüksek malzemelerin ve fosil yakıtların yakılmasıyla ortaya } \\
\text { çıkmaktadır. Ayrıca kükürt oranı yüksek olan metallerin eritilmesiyle de ortaya } \\
\text { çımaktadır. Isınmada, sanayide ve trafikte oluşan bir kirleticidir. }\end{array}$ \\
\hline Karbonmonoksit & $\mathrm{CO}$ & & $\begin{array}{c}\text { Renksiz, kokusuz, tatsız ve zehirli bir gazdır. Karbon içeren yakıtların eksik yanması } \\
\text { sonucu oluşur. Birincil bir hava kirletici olan karbonmonoksit, fosil yakıtlı araçlar } \\
\text { veya makinelerden kaynaklı oluşabilir. }\end{array}$ \\
\hline Azotdioksit & $\mathrm{NO} 2$ & & $\begin{array}{l}\text { İnsan sağllğını en çok etkileyen azot oksit türü olduğu için şehirlerde en önemli hava } \\
\text { kirleticilerindendir. Isınmada, sanayide ve trafikte oluşan bir kirleticidir. }\end{array}$ \\
\hline Azot Oksitler & NOX & & $\begin{array}{l}\text { İnsan sağlığını olumsuz etkileyen azot oksitler şehirlerde en önemli hava } \\
\text { kirleticilerinden biridir. Isınmada, sanayide ve trafikte oluşan bir kirleticidir. }\end{array}$ \\
\hline Ozon & $\mathrm{O} 3$ & & $\begin{array}{c}\text { Yer seviyesindeki ozon kirliliği doğrudan havaya yayılmaz. Güneş ışı̆̆ııın } \\
\text { varlığıyla, atmosfere yayılan azot oksitler ve uçucu organik bileşiklerin kimyasal } \\
\text { reaksiyonları sonucunda oluşmaktadır. Azot oksit ve uçucu organik kirleticiler bu } \\
\text { nedenle ozonun öncül kirleticileri olarak da tanımlanmaktadır. Azot oksitler ve uçucu } \\
\text { organik kirleticilerinin temel kaynakları olan trafik, ssınma ve sanayi tesisleri dolaylı } \\
\text { olarak yer seviyesinde ozon kirliliğine sebep olmaktadır. }\end{array}$ \\
\hline
\end{tabular}


Derin öğrenme yöntemleri son zamanlarda doğal dil işleme ve gerçek zamanlı nesne algılama gibi birçok problemin çözümünde yaygın olarak kullanılmaktadır (Ravi vd., 2017; Young vd., 2018; Şeker, Diri \& Balık, 2017). Literatürde, veri kümesine ve problemin türüne göre çok farklı derin öğrenme modelleri bulunmaktadır. Zamana bağlı değişen süreçlerde bazı derin yöntemleri yetersiz kalmaktadır. Tekrarlayan Sinir Ağları (RNN) zamana bağlı ilişkiler içeren veri kümelerinde başarılıdır (Samarawickrama \& Fernando, 2017). RNN modeli ilk kez 1980'li yıllarda tanıtılmıştır (Buduma \& Locascio, 2017). Bununla birlikte, geleneksel RNN yöntemleri, girdi verisindeki uzun süreli bağımlılıkları yakalama sorunuyla karşı karşıyadır. Bu sorunu çözmek için uzun bir kısa süreli bellek ağı (LSTM) önerilmiştir (Hochreiter \& Schmidhuber, 1997).

Bu çalışmada, Ulusal Hava Kalitesi İzleme Ağı (UHKİA) açık ölçüm verisi kullanılarak kirletici parametreler arasında bulunan PM10 verisinin tahmini üzerine çalışma yapılmış ve LSTM tabanlı derin öğrenme yöntemi önerilmiştir. Çalışma alanı İç Anadolu Bölgesi'nde ve çevresinde bulunan, Tablo 2'de verilen kirleticilerin ölçüldüğü istasyonlarla sınırlandırılmıştır. Gerçek veriler üzerinde önerilen LSTM tabanlı yöntemin performansı ile klasik derin öğrenme (DL) yönteminin performansı karşılaştırılmıştır.

\section{Materyal ve Metot}

\subsection{Veri Kümesi}

$\mathrm{Bu}$ çalışmada Ulusal Hava Kalitesi İzleme Ağı (UHKİA) tarafından ölçülen istasyonlara ait veriler kullanılmıştır. Araştırma uzayı İç Anadolu Bölgesi'nde ve çevresinde bulunan ve Tablo 1'de bulunan 7 kirletici maddeyi de ölçen istasyonlarla sınırlandırılmıştır. Seçili istasyonlardan 01.07.2021 tarih ve 00:00 saati ile 03.09.2021 tarih ve 23:00 saati arasındaki veriler kullanılmıştır. İlgili dataset saatlik bazda veri içermektedir. MGM istasyon konumları Google Earth programı kullanarak işaretlendiğinde Şekil 1'de sunulduğu üzere konumlanmaktadır. (Google Earth, 2021)

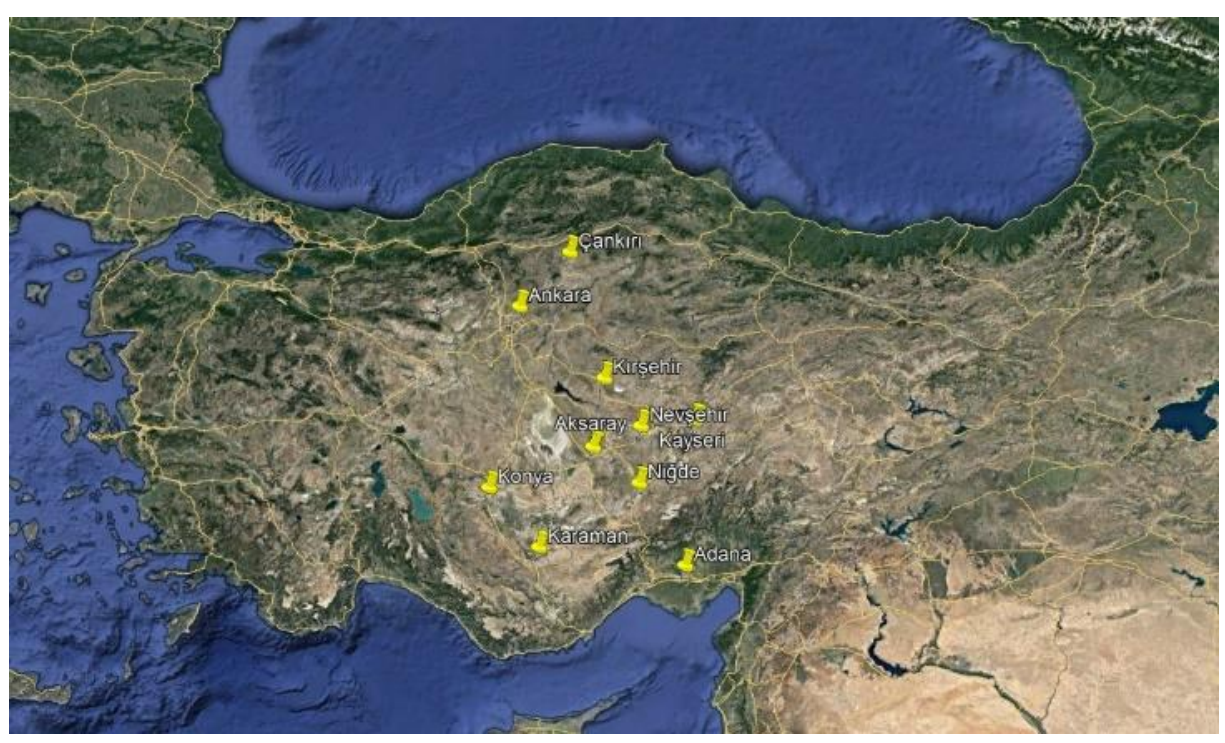

Şekil 1. MGM İstasyon Konumları

Kullanılan veri kümesindeki her istasyondan her saat veri gelmemektedir. Kayıp veri satırları silinerek öğrenmede oluşabilecek sıkıntının önüne geçilmiştir. Veri setinde kullanılan istasyonların isimleri ve kayıp verinin silinmesi ile kalan veri sayısı Tablo 2'de verilmiştir.

\section{Tablo 2. Veri Seti}

\begin{tabular}{l|l|c}
\hline İstasyon ID & İstasyon Adı & $\begin{array}{c}\text { Veri } \\
\text { Sayısı }\end{array}$ \\
\hline 1 & Adana Valilik & 1204 \\
\hline 2 & Adana Yakapınar & 1255 \\
\hline 3 & Aksaray & 1396 \\
\hline 4 & Ankara Sıhhıe & 372 \\
\hline 5 & Ankara Yaşamkent & 559 \\
\hline 6 & Ankara Siteler & 420 \\
\hline 7 & Çankırı & 1437 \\
\hline 8 & Karaman & 1509 \\
\hline 9 & Kayseri OSB & 1434 \\
\hline
\end{tabular}

\begin{tabular}{l|l|c}
\hline 10 & Kırşehir & 1465 \\
\hline 11 & Konya Karkent & 1550 \\
\hline 12 & Konya Erenköy Belediye & 931 \\
\hline 13 & Konya Karatay Sunaypark & 1082 \\
\hline 14 & Nevşehir & 1493 \\
\hline 15 & Niğde & 962 \\
\hline
\end{tabular}

\subsection{Metot}

\subsubsection{Long Short-Term Memory (LSTM)}

Derin öğrenme algoritmalarından biri olan LSTM, Hochreiter ve Schmidhuber tarafından RNN mimarisinin dezavantajlarını yok etmek için ortaya atılan bir tekrarlayan sinir ağı olarak bilinmektedir (Chakraborty vd., 1992). LSTM ağının en önemli özelliği ă̆ ile ilgili geçmiş bilgileri de değerlendirmesidir. Temel LSTM diyagramı Şekil 2'de verilmiştir (Duan \& Wang, 2016; Samui vd., 2018). 


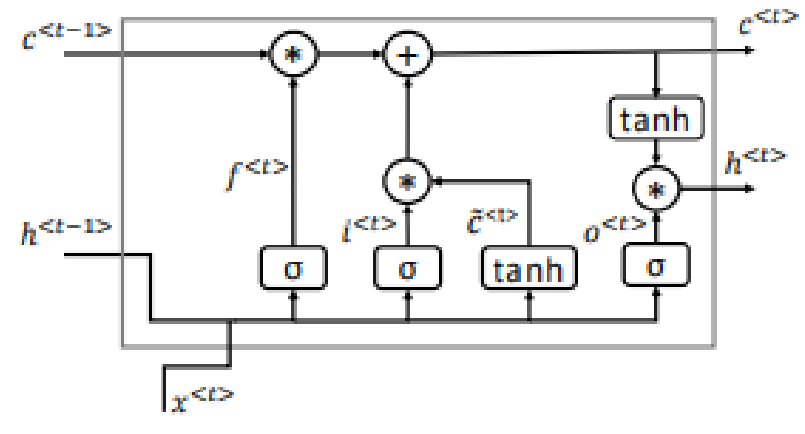

Şekil 2. Temel LSTM blok diyagramı

LSTM ağları, üç iç hücre kapısına bölünerek RNN modelinin kaybolan gradyanları sorununu ele alır ve bilgileri uzun menzilli bir bağlamda depolamak için sözde bellek hücreleri oluşturur (Gers vd., 2000). Tipik bir LSTM yapay sinir ağı hücresi giriş kapısı, giriş modülasyon kapısı, unutma kapısı ve çıkış kapısı olmak üzere temel olarak dört kapı ile yapılandırılır: Hücre kapılar tarafından kontrol edilir ve kapının durumuna göre değeri koruyabilir veya değeri sıfırlayabilir. Özellikle, mevcut hücre değerinin unutulup unutulmayacağını (unut kapısı ft), girişini okuyup okumayacağını (giriş kapısı it) ve yeni hücre değerini çıkışını (çıkış kapısı ot) kontrol etmek için üç kapı kullanılır; ek olarak, ct adında bir giriş modülasyon kapısı vardır. LSTM ağı kapıları ve yürüttükleri işlemler, denklemler 1-6'da sunulmuştur.

$f_{t}=\sigma\left(W_{x f} x_{t}+W_{h f} h_{t-1}+b_{f}\right)$

$\mathrm{i}_{t}=\sigma\left(W_{x i} x_{t}+W_{h i} h_{t-1}+b_{i}\right)$

$\overline{\mathrm{c}}_{t}=\tanh \left(W_{x c} x_{t}+W_{c h} h_{t-1}+b_{c}\right)$

$\left.\mathrm{c}_{t}=f_{t} c_{t-1}+i_{t} \bar{c}_{t}\right)$

$\mathrm{o}_{t}=\sigma\left(W_{x o} x_{t}+W_{h o} h_{t-1}+b_{o}\right)$

$\mathrm{h}_{t}=\mathrm{o}_{t} * \tanh \left(\mathrm{c}_{t}\right)$

Giriş kapısı dışarıdan yeni bir giriş noktası alır ve yeni gelen verileri işler. Bellek hücresi giriş kapısı, son yinelemede LSTM yapay sinir ağı hücresinin çıkışından girdi alır. Unut kapısı, çıktı sonuçlarının ne zaman unutulacağına karar verir ve böylece giriş dizisi için en uygun zaman gecikmesini seçer. Çıkış kapısı, hesaplanan tüm sonuçları alır ve LSTM yapay sinir ağı hücresi (Hochreiter \& Schmidhuber, 1997) için çıtı üretir. LSTM modelleri, RNN ağının yapısına dayalı olarak bilgi işlem düğ̈ümlerini yeniden tasarlar.

\section{Araştırma Sonuçları ve Tartışma}

Klasik derin öğrenme ve LSTM yöntemlerinin deneysel değerlendirmeleri Çevre ve Şehircilik Bakanlığından alınan gerçek veriler kullanılarak yapılmıştır. Yöntemlerin başarım performansını irdelemek için değerlendirme kriteri ortalama mutlak hata (MAE) ve ortalama hata kare kökü (RMSE) değerleri kullanılmıştır. Deneysel değerlendirme yapılan istasyon bilgileri ve yöntemlerin değerleri Tablo 3 ve Tablo 4'te sunulmuştur.

Deneysel sonuçlarının MAE metriği ile değerlendirilmesi sonucu oluşan Tablo 3 incelendiğinde LSTM yönteminin DL yöntemine kıyasla her zaman daha düşük hata sonuçları verdiği görülmektedir. Değerlendirme sonuçlarındaki hata oranlarının daha görsel açıklanması için Şekil 3'teki MAE değerlerine ait grafik oluşturulmuştur.

Tablo 3. Metotların MAE Hata Değgerleri

\begin{tabular}{l|c|c}
\hline İstasyon ID & Derin Öğrenme & LSTM \\
\hline 1 & 13,327 & 10,802 \\
\hline 2 & 15,238 & 4,814 \\
\hline 3 & 26,165 & 10,507 \\
\hline 4 & 14,357 & 8,657 \\
\hline 5 & 19,192 & 6,779 \\
\hline 6 & 26,286 & 5,946 \\
\hline 7 & 12,512 & 7,316 \\
\hline 8 & 6,727 & 2,755 \\
\hline 9 & 15,696 & 5,222 \\
\hline 10 & 13,498 & 6,612 \\
\hline 11 & 15,766 & 4,963 \\
\hline 13 & 20,218 & 8,767 \\
\hline 14 & 14,161 & 6,646 \\
\hline 15 & 10,782 & 3,688 \\
\hline
\end{tabular}

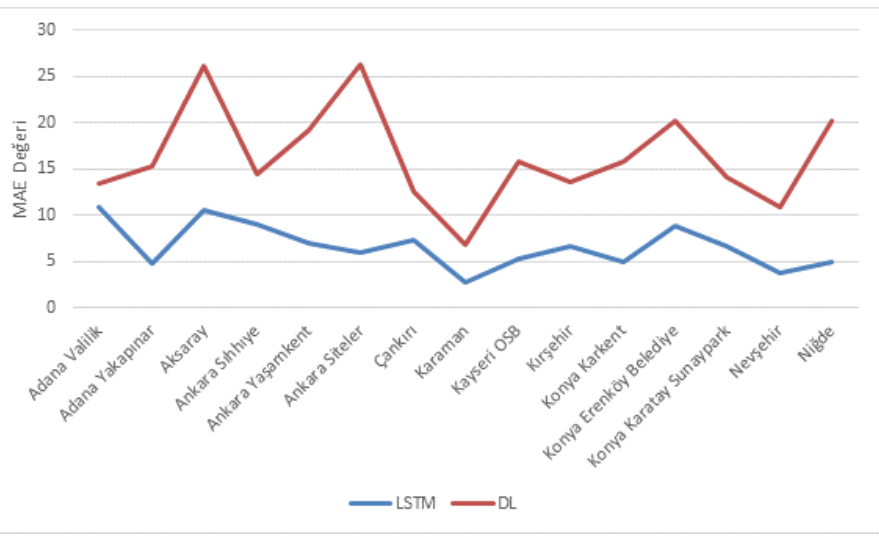

Şekil 2. Metotların MAE değerlerinin kıyaslanması

LSTM ve DL yönteminin kıyaslanması için ikincil olarak RMSE metriği kullanılmıştır. Deney sonucu oluşan hata değerleri Tablo 4'te veriliştir.
İstasyonlarda her saat veri alınamaması sebebiyle oluşan veri kaybından yöntemlerin etkilenme oranlarını değerlendirebilmek için RMSE değerleri ile veri sayısı arasındaki oran Şekil 4'te 
grafik haline getirilmiştir. Seçilen modelin veri sayısındaki değişimden minimum etkilenmesi beklenir. Grafikte de görüldüğü üzere veri kaybından en az etkilenen yöntem seçilen LSTM modelidir.
Tablo 4. Metotların RMSE Hata Değerleri

\begin{tabular}{l|c|c}
\hline İstasyon ID & Derin Öğrenme & LSTM \\
\hline 1 & 18,312 & 14,378 \\
\hline 2 & 22,150 & 7,040 \\
\hline 3 & 41,334 & 20,941 \\
\hline 4 & 18,568 & 10,387 \\
\hline 5 & 22,883 & 8,791 \\
\hline 6 & 30,650 & 7,435 \\
\hline 7 & 15,881 & 9,215 \\
\hline 8 & 8,668 & 3,852 \\
\hline 9 & 20,690 & 8,020 \\
\hline 10 & 19,940 & 13,323 \\
\hline 11 & 19,906 & 6,498 \\
\hline 12 & 24,911 & 12,036 \\
\hline 13 & 17,604 & 9,267 \\
\hline 14 & 13,376 & 4,738 \\
\hline
\end{tabular}

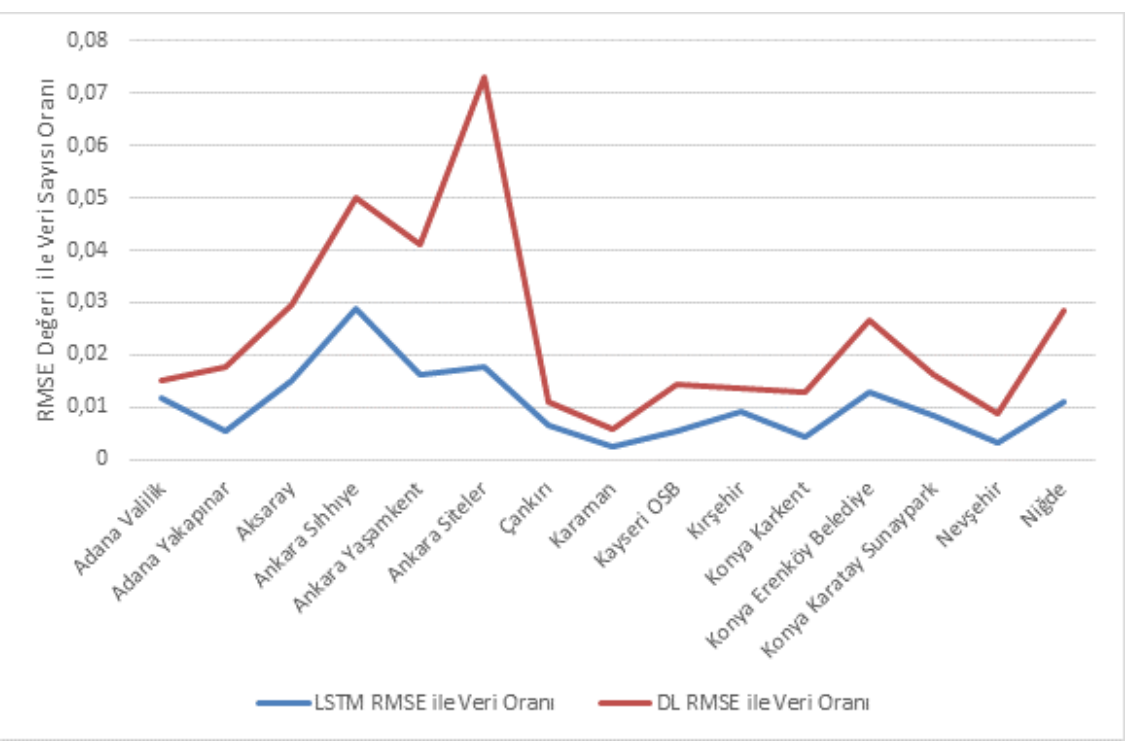

Şekil 3. Metotların RMSE Değeri ile Veri Sayısı Arasındaki İlişki

\section{Sonuç}

Hava kirliliğinin artması ve buna bağlı olan sebeplerin araştırılması günümüzde ilgi çeken bir konudur. Hava kirliliğine etki eden kirleticilerin önlenebilmesi için tahmin edilebilmesi önemlidir. Bu çalışmada kirleticiler arasında yüksek riskli olarak değerlendirilen partikül madde yoğunluğunun tahmin edilmesi amaçlanmıştır.

Çalışmada kullanılan klasik derin öğrenme yaklaşımı ile önerilen LSTM yöntemine göre hata değerlerine göre değerlendirildiğinde başarısız çıkmıştır. Ayrıca kullanılan verideki kaybın da sonuçları etkilediği görülmüş, klasik derin öğrenme ve LSTM yöntemleri veri kaybına göre değerlendirilmiştir; sonuç olarak LSTM'in diğer yöntemlere kıyasla daha stabil değerler verdiği gözlenmiştir.

\section{Kaynakça}

Buduma, N., \& Locascio, N. (2017). Fundamentals of Deep Learning: Designing Next-Generation Machine Intelligence Algorithms.

Chakraborty, K., Mehrotra, K., Mohan, C. K., \& Ranka, S. (1992). Forecasting the behavior of multivariate time series using neural networks. Neural Networks, 5(6), 961-970. https://doi.org/10.1016/S0893-6080(05)80092-9

Duan, Y., Lv, Y., \& Wang, F. Y. (2016). Travel time prediction with LSTM neural network. IEEE Conference on Intelligent Transportation Systems, Proceedings, ITSC, 1053-1058. https://doi.org/10.1109/ITSC.2016.7795686

Gers, F.A., Schmidhuber, J., \& Cummins, F.A. (2000). Learning to Forget: Continual Prediction with LSTM. Neural Computation, 12, 2451-2471. 
Google Earth, (2021, 5 Ekim) erişim adresi: https://earth.google.com

Hava Kalitesi Değerlendirme ve Yönetimi Yönetmeliği. (2008, 06 Haziran). Resmi Gazete (Sayı: 26898). Erişim adresi: https://www.resmigazete.gov.tr/eskiler/2008/06/200806066.htm

Hochreiter, S., \& Schmidhuber, J. (1997). Long Short-Term Memory. Neural Computation, 9, 1735-1780. doi: https://doi.org/10.1162/neco.1997.9.8.1735

Kirletici Parametre Ayarları, (2021, 5 Ekim) Erişim adresi: https://sim.csb.gov.tr/Intro/ParametersMeta

Li, X., Jin, L., \& Kan, H. (2019). Air pollution: a global problem needs local fixes. Nature, 570(7762), 437-439. https://doi.org/10.1038/d41586-019-01960-7

Lu, F., Xu, D., Cheng, Y., Dong, S., Guo, C., Jiang, X., \& Zheng, $X$. (2015). Systematic review and meta-analysis of the adverse health effects of ambient PM2.5 and PM10 pollution in the Chinese population. Environmental Research, 136, 196-204. https://doi.org/10.1016/J.ENVRES.2014.06.029

Ravì, D., Wong, C., Deligianni, F., Berthelot, M., Andreu-Perez, J., Lo, B.P., \& Yang, G. (2017). Deep Learning for Health Informatics. IEEE Journal of Biomedical and Health Informatics, 21, 4-21.

Samarawickrama, A.J., \& Fernando, T.G. (2017). A recurrent neural network approach in predicting daily stock prices an application to the Sri Lankan stock market. 2017 IEEE International Conference on Industrial and Information Systems (ICIIS), 1-6.

Samui, S., Chakrabarti, I., \& Ghosh, S.K. (2018). Tensor-Train Long Short-Term Memory for Monaural Speech Enhancement. ArXiv, abs/1812.10095.

Scapellato, M. L., Canova, C., de Simone, A., Carrieri, M., Maestrelli, P., Simonato, L., \& Bartolucci, G. B. (2009). Personal PM10 exposure in asthmatic adults in Padova, Italy: seasonal variability and factors affecting individual concentrations of particulate matter. International Journal of Hygiene and Environmental Health, 212(6), 626-636. https://doi.org/10.1016/J.IJHEH.2009.06.001

Şeker, A., Diri, B., \& Balik, H.H. (2017). Derin Öğrenme Yöntemleri ve Uygulamaları Hakkında Bir İnceleme.

Turner, M. C., Krewski, D., Pope, C. A., Chen, Y., Gapstur, S. M., \& Thun, M. J. (2011). Long-term Ambient Fine Particulate Matter Air Pollution and Lung Cancer in a Large Cohort of Never-Smokers. American Journal of Respiratory and Critical Care Medicine, 184(12), 1374-1381. https://doi.org/10.1164/rccm.201106-1011OC

Janssen, N. A. H., Fischer, P., Marra, M., Ameling, C., \& Cassee, F. R. (2013). Short-term effects of PM2.5, PM10 and PM2.510 on daily mortality in the Netherlands. Science of The Total Environment, 463-464, 20-26. https://doi.org/10.1016/J.SCITOTENV.2013.05.062

Wu, S., Deng, F., Hao, Y., Wang, X., Zheng, C., Lv, H., Lu, X., Wei, H., Huang, J., Qin, Y., Shima, M., \& Guo, X. (2014). Fine particulate matter, temperature, and lung function in healthy adults: Findings from the HVNR study.
Chemosphere,

108

$168-174$ https://doi.org/10.1016/J.CHEMOSPHERE.2014.01.032

Young, T., Hazarika, D., Poria, S., \& Cambria, E. (2018). Recent Trends in Deep Learning Based Natural Language Processing [Review Article]. IEEE Computational Intelligence Magazine, 13, 55-75.

Zeydan, Ö. (2021). 2019 Yilında Türkiye'deki Partikül Madde (PM10) Kirliliğinin Değerlendirilmesi. Journal of the Institute of Science and Technology, 11 (1), 106-118. DOI: $10.21597 /$ jist.745539 